\title{
PHENOTYPING, VIRULENCE CHARACTERISTICS OF AEROMONAS SPECIES AND THE EFFECTS OF ESSENTIAL PLANT OILS AS ANTIMICROBIAL AGENTS AGAINST PATHOGENIC ISOLATES FROM DIFFERENT SOURCES
}

\author{
${ }^{1}$ Ahmed M.A. Mansour, ${ }^{1,2}$ Hoda M. Zaki, ${ }^{1,3}$ Nibal A. Hassan and ${ }^{4}$ Nihad A.M. El-Nashar \\ ${ }^{1}$ Department of Medical Laboratory, Faculty of Applied Medical Sciences, Taraba, Taif University, KSA \\ ${ }^{2}$ Department of Brucella, Animal Health Research Insitute, Dokki, Giza, Egypt \\ ${ }^{3}$ Department of Pathology of Reproduction, Animal Reproduction Research Insitute, El-Harm, Giza, Egypt \\ ${ }^{4}$ Department of Pathology, Faculty of Medicine, Taif University, KSA
}

Received 2013-12-21; Revised 2014-01-06; Accepted 2014-01-18

\begin{abstract}
Aeromonas species are increasingly recognized as enteric pathogens. Faecal samples from 20 cow, 45 sheep; 60 goat and 60 camels were examined for the presence of Aeromonas species, which was also sought in the available drinking water (55 well water and 52 drinking chlorinated tap water were also examined). Aeromonas species was isolated more frequently from goats $(21.7 \%)$ than from other animal groups sampled and isolated more frequently from well water (38.2\%) than chlorinated supplies (23.0\%). A. hydrophilia was the most dominant species isolated from different kinds of samples (13.4\%). Whereas $A$. sobria and $A$. caviae were isolated in much lower rates 4.7 and $2.1 \%$ respectively. There was significant association between the isolation of Aeromonas species from all animal faeces and its presence in drinking water. All isolated strains were examined for the characteristics that are reputed to have roles in pathogenicity. The data reported in this study indicates that the distributions of virulence factors, that regulate the pathogenicity of Aeromonads, are different in clinical and enviromental samples. Aeromonas isolates exhibited multi-drug resistanc amoxicillin, carbenicillin and ampicillin. The most potent antibiotics against Aeromonas species isolated in this study were ceftriaxone, ceftazidime, cefotaxime, cefepime. Essential oils have been tested for in vitro and in vivo antimicrobial activity. Clove, Olive and Peppermint oil exhibited a wide spectrum of antimicrobial activity against all strains used in this study, showed a zone of inhibition ranging from $10.00 \pm 0.8$ to $14.82 \pm 0.41 \mathrm{~mm}$ in diameter. Minimum Inhibitory Concentration (MIC) for selected oils ranged from 12.8 to $25.6 \mathrm{mg} \mathrm{mL}^{-1}$. Treatment of mice with essential oil for 15 days led to enhance antibody levels in all treated groups and significant clearance of A. hydrophilia from animals. The treated animals had minimal histopathological changes and lower bacterial loads in the organs examined. In conclusion, these findings indicate that aeromonads have the potential to cause human illness and confirm the role of water as vehicles for Aeromonas diseases. This study also demonstrated that the multi-factorial nature of the diseases and the influence of environmental conditions in the expression of the putative virulence properties. These results suggested the potential value of essential oils as an additional or supporting treatment in gastrointestinal inflammations.
\end{abstract}

Keywords: Aeromoans Species, Plant Oils, Antibiotics, Clove, Olive and Peppermint Oil

\section{INTRODUCTION}

Aeromonas species are facultative anaerobic Gramnegative bacteria that belong to the family
Aeromonadaceae which are found in sea, river, fresh and ground water (Hassan et al., 2012). There are accumulating data indicating that Aeromonas hydrophila (A. hydrophila) is the causative agent for several diseases

Corresponding Author: Ahmed M.A. Mansour, Department of Medical Laboratory, Faculty of Applied Medical Sciences, Taraba, Taif University, KSA 
in cold blooded animals including fish and reptiles and in warm-blooded animals such as mammals and birds (Kuhn et al., 1997). In humans, Aeromonas causes diarrhea, gastroenteritis and extraenteritic conditions such as septicemia, wound infection, endocarditis, meningitis and pneumonia (Ali and Hossein, 2010). There is little information on the incidence of Aeromonas species in mammals, other than man. Wohlgemuth et al. (1972) isolated it from a case of bovine abortion and Sanyal et al. (1975) isolated it from the faeces of a calf. Annapurna and Sanyal (1977) isolated A. hydrophila from faeces of domestic animals-cow, buffalo, goat and chickens-although no large-scale study has been reported to date. Moreover, there are reports indicating that $A$. hydrophila in particular is one of the food borne pathogens in seafood and shellfish and in foods from other sources such as raw red meat, poultry, dairy products and vegetables (Daskalov, 2006). The pathogenesis of Aeromonas infection is complex and multifactorial. Aeromonas species secretes many extracellular proteins, including amylase, chitinase, elastase, aerolysin, nuclease gelatinase, lecithinase, lipase and protease. These proteins are known as virulence factors that cause disease in fish and humans. Aerolysin is a representative virulence factor of Aeromonas and was reported to function as hemolysins and cytolytic enterotoxins (Bhowmik et al., 2009).

Antibiotic resistance and reduced efficacy of the contemporary drugs due to intense usage of antimicrobial agents has been identified in animal pathogens (Grim et al., 2013). Additionally, antibiotic resistance can be transmitted horizontally from one bacterium to another and this way can be passed through human pathogens (Okmen et al., 2012). Finally, antibiotics can accumulate in animals which create a potential risk for the consumers (FAO\OIEIWHO, 2006). All these outcomes reported from agricultural industries increased awareness towered the negative impacts of indirect exposures to antimicrobial agents. This increasing public awareness led to search for green solutions such as organic food products that are free of organic or synthetic chemicals. Medicinal plants have been used for treatment of common infections since ancient times (Turker et al., 2009). Hence, it is important to isolate and determine the frequency of occurrence of Aeromonas species in the natural surface waters and clinical samples from different animals and to characterize them in detail. We report here its ability to produce virulence-associated factors as well as to determine the antibiotic profile of isolated Aeromonas species. The aim of this study also was to investigate the antimicrobial potential of three different plant essential oils (Clove, Olive and Peppermint oils) against the selected Aeromonas species isolates.

\section{MATERIALS AND METHODS}

\subsection{Study Area and Sample Collection}

In kingdom of Saudi Arabia, different sites located in Taif governorate and its surroundings, were selected.

\subsection{Faecal Samples}

A Total of 185 Faecal samples (20 from cow; 45 from sheep; 60 from goat and 60 from camels) were collected from diseased animals.

Faecal samples (rectal contents) were taken from rectum under a separate polyethylene bag.

Most establishments at which animals were sampled had well (untreated) water as the available drinking water.

\subsection{Water Samples}

A total of 107 water samples (55 well water and 52 drinking chlorinated tap water) were collected bi-weekly from January 2013 to Septemper 2014.

Wells water samples were collected in sterile $250 \mathrm{~mL}$ glass bottles ( $5 \mathrm{~cm}$ below the water surface).

These water sources are used for drinking animals and for domestic purposes such as bathing, washing of clothes and utensils and cooking, by the community.

From each available chlorinated drinking tap water, about $300 \mathrm{~mL}$ a sample was also collected in a sterile water sampling bottle. Inoculations into selective media were conducted within $24 \mathrm{~h}$ after collection of the water samples.

\subsection{Isolation and Identification of Bacteria}

Ten milliliters of each water sample or $5 \mathrm{~g}$ of each fecal sample was inoculated into $10 \mathrm{~mL}$ double-strength alkaline Peptone water ( $\mathrm{PH} 8.6)$ and incubated at $37^{\circ} \mathrm{C}$ for $24 \mathrm{~h}$. A sample from this enrichment culture was streaked with a loop on Thiosulfate-Citratebile SaltsSucrose (TCBS) agar (Eiken) and incubated for $24 \mathrm{~h}$ at $37^{\circ} \mathrm{C}$ (Kuhn et al., 1997).

\subsection{Identification of Aeromonas Species}

The biochemical reactions of Aeromonas species were given in Table 1 (Using Cowan and Steel"s Manual for the Identification of Medical Bacteria (3rd Edition):

- Detection of extracellular enzymes: (Protease, gelatinase and haemolysis production) 
- Protease activity was assayed by method described by Sechi et al. (2002)

- Gelatinase production was determined using Luria Broth agar containing gelatine $\left(30 \mathrm{~g} \mathrm{~L}^{-1}\right)$, as described by Sechi et al. (2002)

- Hemolysin production was assayed as described by Santos et al. (1999)

- Cytotoxin production

- Preparation of cell-free culture supernatants. Trypticase Soy Broth (TSB; Hi Media) was used for assessing production of various toxins and the cell-free filtrate was used for the tissue culture (Bhowmik et al., 2009)

- Tissue culture assay. The tissue culture assay was performed using HEp-2 cells as described previously (Bag et al., 2008). Morphological changes and cytotoxic effects were recorded after $24 \mathrm{~h}$ incubation using an inverted microscope (Olympus)

- Adhesion to epithelial cells HEp-2 cells were used for the adhesion assay as reported by Sechi et al. (2002)

- Slime test The test was performed according to Freeman et al. (1989)

- Crystal violet binding. The ability of Aeromonas species to bind crystal violet was determined as described by Paniagua et al. (1990)

- Hemagglutination test. The method described by Atkinson and Trust (1980) was followed for the evaluation of the hemagglutination ability of strains

- Serum resistance test. The susceptibility of bacteria to human serum was determined as described previously by Bag et al. (2008)

\subsection{Antibiotic Susceptibility Testing}

Aeromonas spp. strains isolated in the present study were subjected to susceptibility testing against 28 antimicrobials commonly used. Susceptibility was determined by the disk-diffusion technique of KirbyBauer on Mueller-Hinton agar plates (Oxoid Basingstoke, UK) with inocula adjusted to an optical density of 0.5 McFarland standard units (CLSI, 2010). Disks containing Ampicillin (AMP10 $\mu \mathrm{g}$ ), Carbenicillin (CAR100 $\mu \mathrm{g}$ ), Amoxicillin (AML10 $\mu \mathrm{g}$ ), Amoxicillin/ Clavulanic acid (AMC30 $\mu \mathrm{g}$ ), piperacillin (PRL100 $\mu \mathrm{g}$ ), piperacillin/tazobactam (TZP110 $\mu \mathrm{g}$ ), Ticarcillin (TIC75 $\mu \mathrm{g}$ ), Ticarcillin/clavulanic acid (TIM85 $\mu \mathrm{g}$ ), cephalothin $(\mathrm{KF} 30 \mu \mathrm{g})$, Cefoxitin (FOX30 $\mu \mathrm{g}$ ), Cefotaxime (CTX30 $\mu \mathrm{g})$, Cefoperazone (CFP30 $\mu \mathrm{g})$, cef-Tazidime (CAZ30 $\mu \mathrm{g})$, Ceftriaxone (CRO30 $\mu \mathrm{g})$, Cefepime (FEP30 $\mu \mathrm{g}$ ), Aztreonam (ATM30 $\mu \mathrm{g}$ ), Imipenem (IMP10 $\mu \mathrm{g}$ ), gentamicin (CN10 $\mu \mathrm{g})$, Kanamycin (K30 $\mu \mathrm{g})$,
Tobramycin (TOB10 $\mu \mathrm{g})$, Amikacin (AK30 $\mu \mathrm{g})$, Netilmicin (NET30 $\mu \mathrm{g})$, tetracycline (TE30 $\mu \mathrm{g}$ ), ciprofloxacin (CIP5 $\mu \mathrm{g}$ ), Norfloxacin (NOR10 $\mu \mathrm{g}$ ), Erythromycin (E15 $\mu \mathrm{g})$, Trimethoprim/Sulfamethoxazole $($ SXT25 $\mu \mathrm{g})$ and Ch-Loramphenicol (C30 $\mu \mathrm{g})$ were used. All disks were obtained from Oxoid. After $24 \mathrm{~h}$ incubation at $30^{\circ} \mathrm{C}$, organisms were classified as Sensitive (S), Intermediately resistant (I) or Resistant (R) on the basis of the size of the zone of bacteria growth inhibition according to the guidelines of the CLSI (2010).

\subsection{Essential Oils}

Clove, Olive and Peppermint oils used in this study were obtained from Aggarwal's Pharmaceuticals (Delhi, India) and SK Products (Meerut, India). Stock solutions were prepared by emulsifying oils (5\%) in distilled water. The oils were sterilized at $10 \mathrm{lb}$ for $30 \mathrm{~min}$ before use.

Determination of antimicrobial activity of essential oils and their principal constituents: The antimicrobial activity was investigated using a modified agar well diffusion technique (Wan et al., 1998).

Determination of Minimum Inhibitory Concentrations (MIC): The agar dilution method recommended by the National Committee for Clinical Laboratory Standards (Prudent et al., 1995) was used with modification described by (Delaquis et al., 2002).

\subsection{Animals and Treatments}

About 50 mice male $\mathrm{BALB} / \mathrm{c}$ mice, aged 6 to 8 weeks and weighing $25 \pm 5 \mathrm{~g}$ (Biological Supply Center, King Fahd Centre for Medical Researches, College of Medicine, King Abdul-Aziz University, Jeddah, KSA) were used. The animals were disease-free. Animals were divided into five groups, each of which contained randomly selected 10 mice were housed in propylene cages and had free access to an antibioticfree diet and water ad libitum. The photoperiods were adjusted daily to a cycle of $12 \mathrm{~h}$ of light and $12 \mathrm{~h}$ of darkness. The environmental temperature and relative humidity was constantly maintained at $21 \pm 2^{\circ} \mathrm{C}$ and 50-70\%, respectively.

Groups of 10 mice were fed on a standard laboratory chow diet with with oral supplementation of $1 \%(\mathrm{w} / \mathrm{v})$ clove oil $0.5 \mathrm{~mL}$ (group1), $5 \%(\mathrm{w} / \mathrm{v})$ olive oil $0.5 \mathrm{~mL}$ (group2) or 5\% (w/v) Peppermint oil $0.5 \mathrm{~mL}$ (group3) for 15 days (Farzaneh et al., 2011). Control positive mice (group4) were fed on a standard laboratory chow diet and received daily oral normal saline $0.5 \mathrm{~mL}$ for 15 days. A. hydrophlia strain was isolated from clinical source and positive to all virulence tests used for challenge of all animal groups. All animal groups 
were injected intramuscularly in the left hindquarter of each test mouse with of A. hydrophila bacterial suspension $(0.1 \mathrm{~mL} ; 3 \times 107 \mathrm{cfu})$. Control negative mice (group5) were fed on a standard laboratory chow diet and not infected.

\subsection{Mortality Rates}

Mortality rates calculated as numbers of dead mice all over the experimental period in relation to all inoculated mice in each group.

\subsection{Samples Collected From Experimental Animals}

Blood samples were collected from all mice each group 1, 2, 3 and 4 weeks post-challenge of $A$. hydrophilia. The serum was separated by centrifugation and stored at $-20^{\circ} \mathrm{C}$ until used for ELISA testing for the final titers of $\mathrm{IgG}$ to assess the potential therapeutic and eradicative effect of essential oil against $A$. hydrophila.

The post mortem examination was performed either on the dead mice all over the experiment within $15 \mathrm{~min}$ of death or to the sacrificed mice after the end of the experiment. Tissues specimens were collected from all animals (intestine, lung, liver and spleen) and divided into 2 portions, first part subjected to bacteriological examination for isolation and identification of $A$. hydrophila while the second one were fixed in $10 \%$ buffered neutral formalin for histopathological studies (Chang and Miller, 2006).

Exraction of cell envelopes. Cell envelopes were extracted from A. hydrophila isolated strain as described by Lugtenberg et al. (1975).
Indirect ELISA. The indirect ELISA was performed to measure antibody responses in all mouse sera against cell envelopes of $A$. hydrophilia according to the method described by Tissen (1985).

\section{RESULTS}

\subsection{Isolation and Identification of Aeromonas Species}

Analysis of the data presented in Table $\mathbf{2}$ showed that, overall, Aeromonas was isolated more frequently from goats $(21.7 \%)$ than from other animal groups sampled, whilst camels had the lowest rate of isolation $(8.3 \%)$. Faces from cow and sheep revealed the isolation of Aeromonas species 10 and $13.3 \%$ respectively. All animals exhibited the diarrheic consistency of stool associated with the diseased animals. Aeromonas species was isolated more frequently from well water $38.2 \%$ (21 of 55 tested samples) than chlorinated supplies $23.0 \%$ (12 of 52 tested samples). A. hydrophilia was the most dominant species isolated from different kinds of samples $13.4 \%$ (39 out of 292 samples). Whereas $A$. sobria and $A$. caviae were isolated in much lower rates $4.7 \%$ (14 out of 292 samples) and $2.1 \%$ (6 out of 292 samples) respectively.

\subsection{Putative Virulence Properties of the Aeromonas Strains}

Relative frequencies of the different virulence properties of Aeromonas spp. (environmental and clinical strains) are given in Table 3.

Table 1. Identification tests applied for Aeromonas species

\begin{tabular}{llll}
\hline Biochemical tests & Aeromonas hydrophila & Aeromonas caviae & Aeromonas sobria \\
\hline Indole production & + & + & + \\
Glucose fermentation & + & + & + \\
Lactose fermentation & + & - & - \\
Acid from sucrose & + & - & - \\
Acid from inositol & + & - & + \\
Gas production from glucose & + & - & + \\
Citrate as C source & + & + & + \\
Arginine hydrolysis & + & + & \\
\hline
\end{tabular}

Table 2. of Aeromonas species from animal faeces and available water samples

\begin{tabular}{|c|c|c|c|c|c|c|c|c|c|c|c|c|c|c|}
\hline \multirow[b]{2}{*}{ Aeromonas species } & \multicolumn{2}{|c|}{ Cows -20} & \multicolumn{2}{|c|}{ Sheep -45 } & \multicolumn{2}{|c|}{ Goats -60} & \multicolumn{2}{|c|}{ Camels -60 } & \multicolumn{2}{|c|}{ Well water -55 } & \multicolumn{2}{|c|}{ Chlorinated tap water } & \multicolumn{2}{|c|}{ Total (292) } \\
\hline & No. & $(\%)$ & No & $(\%)$ & No. & $(\%)$ & No. & $(\%)$ & No. & $(\%)$ & No. & $(\%)$ & No. & $(\%)$ \\
\hline A. hydrophelia & 2 & 10 & 4 & 8.9 & 9 & 15.0 & 3 & 5.0 & 13 & 23.6 & 8 & 15.4 & 39 & 13.4 \\
\hline A. sobria & 0 & 0 & 1 & 2.2 & 4 & 6.7 & 1 & 1.7 & 5 & 9.1 & 3 & 5.8 & 14 & 4.8 \\
\hline A. caviae & 0 & 0 & 1 & 2.2 & 0 & 0.0 & 1 & 1.7 & 3 & 5.5 & 1 & 1.9 & 6 & 2.1 \\
\hline Total & 2 & 10 & 6 & 13.3 & 13 & 21.7 & 5 & 8.3 & 21 & 38.2 & 12 & 23.1 & 59 & 20.2 \\
\hline
\end{tabular}

Percentage calculated according to number of samples collected from different sources 
Ahmed M.A. Mansour et al. / American Journal of Infectious Diseases 10 (1): 21-35, 2014

Table 3. Virulence phenotypes of environmental and clinical isolates of Aeromonas species

\begin{tabular}{|c|c|c|c|c|c|c|c|c|c|c|c|c|c|c|}
\hline \multirow[b]{3}{*}{ Virulence test } & \multicolumn{4}{|c|}{ A. hydrophelia isolates } & \multicolumn{4}{|c|}{ A. sobria isolates } & \multicolumn{4}{|c|}{ A. caviae isolates } & \multicolumn{2}{|c|}{ Total } \\
\hline & \multicolumn{2}{|c|}{ Environmental (21) } & \multicolumn{2}{|c|}{ Clinical (18) } & \multicolumn{2}{|c|}{ Environmental (8) } & \multicolumn{2}{|c|}{ Clinical (6) } & \multicolumn{2}{|c|}{ Environmental (4) } & \multicolumn{2}{|c|}{ Clinical (2) } & \multicolumn{2}{|l|}{ (59) } \\
\hline & No. & $(\%)$ & No & $(\%)$ & No. & $(\%)$ & No. & $(\%)$ & No. & $(\%)$ & No. & $(\%)$ & No. & $(\%)$ \\
\hline Protease & 14 & 66.7 & 16 & 88.9 & 3 & 37.5 & 4 & 66.7 & 1 & 25 & 1 & 50 & 39 & 66.1 \\
\hline Gelatinase & 0 & 00.0 & 9 & 50.0 & 0 & 0.0 & 4 & 66.7 & 0 & 0 & 1 & 50 & 14 & 23.7 \\
\hline Haemolysis & 3 & 14.3 & 7 & 38.9 & 2 & 25.0 & 2 & 33.3 & 1 & 25 & 1 & 50 & 16 & 27.1 \\
\hline Cytotoxin production & 9 & 42.9 & 17 & 94.4 & 3 & 37.5 & 3 & 50.0 & 1 & 25 & 1 & 50 & 34 & 57.6 \\
\hline Adherence assay & 6 & 28.6 & 16 & 88.9 & 4 & 50.0 & 3 & 50.0 & 0 & 0 & 1 & 50 & 30 & 50.8 \\
\hline Slim test & 6 & 28.6 & 16 & 88.9 & 4 & 50.0 & 2 & 33.3 & 0 & 0 & 1 & 50 & 29 & 49.2 \\
\hline Serum resistance & 9 & 42.9 & 17 & 94.4 & 3 & 37.5 & 4 & 66.7 & 0 & 0 & 1 & 50 & 34 & 57.6 \\
\hline Crystal violet binding. & 6 & 28.6 & 12 & 66.7 & 2 & 25.0 & 4 & 66.7 & 0 & 0 & 2 & 100 & 26 & 44.1 \\
\hline Hemagglutination test & 7 & 33.3 & 12 & 66.7 & 3 & 37.5 & 4 & 66.7 & 0 & 0 & 1 & 50 & 31 & 52.5 \\
\hline
\end{tabular}

Protease Skimmed milk was hydrolyzed by $88.9 \%$ of A. hydrophila clinical strains and only by $66.7 \%$ of environmental strains. Whereas $66.7 \%$ clinical strains and $37.5 \%$ environmental strains of $A$. sobria isolates were able to hydrolyze Skimmed milk. Only one $A$. caviae isolate from each environmental and clinical sources was positive for Protease activity in percents of $25.0 \%$ and $50.0 \%$ respectively.

Gelatinase. Fifty percent of A. hydrophila; $66.7 \%$ of A. sobria and $50.0 \%$ A. caviae clinical isolates were gelatinase positive, whereas none of the environmental strains were able to degrade gelatine.

Haemolysin. About $38.9 ; 33.3$ and $50.0 \%$ of clinical A. hydrophila; A. sobria and A. caviae strains were able to lyse rabbit erythrocytes and produced haemolysis on rabbit blood agar plates; slightly lower percentages of environmental A. hydrophila; A. sobria and A. caviae strains $(14.3 ; 25.0$ and $25.0 \%$ respectively) showed the same property.

Cytotoxin production Cytopathic effect was found in $42.9 \%$ of the environmental and in $94.4 \%$ of the clinical A. hydrophila isolates. About $37.5 \%$ of the environmental and $50 \%$ of the clinical $A$. sobria isolates produced a cytopathic effect (Fig. 1b). Finally one $A$. caviae isolate from each environmental and clinical source produced a cytotoxic response to HEp-2.

Adhesion test About 28.6\% environmental and $88.9 \%$ clinical isolates of $A$. hydrophila strains were able to adhere to the epithelial cells, whereas $50.0 \%$ of each environmental and clinical $A$. sobria strains were able to adhere to the epithelial cells Only one A. caviae clinical isolate was able to adhere to the epithelial cells (Fig. 1b, c).

Slime test. The slime production test was positive for $28.6 \%$ of environmental and for $88.9 \%$ of clinical $A$. hydrophila strains tested, whereas 50.0 and $33.3 \%$ of $A$. sobria of environmental and clinical sources respectively were also positive. Only one A. caviae strain of clinical strains tested was positive in the slime test.

Serum resistance The ability of A.hydropilia isolates from environmental and clinical sources to survive in serum was 42.9 and $94.4 \%$ respectively while $37.5 \%$ environmental and $66.7 \%$ clinical $A$. sobria strains were able to survive in serum. Only one clinical $A$. caviae strain was positive.

Crystal violet binding About $28.6 \%$ environmental and $66.7 \%$ clinical A.hydropilia strains were able to bind crystal violet, whereas $25.0 \%$ environmental and and $66.7 \%$ clinical A. sobria strains were able to bind crystal violet. All clinical A.caviae strains were positive.

Hemagglutination test Hemagglutination ability of A.hydropilia tested on sheep blood cells was exhibited by $33.3 \%$ of environmental and 66.7 of the clinical strains. About $37.5 \%$ environmental and $66.7 \%$ clinical A. sobria strains were positive for hemagglutination property. Only one clinical A. caviae strain was positive.

\subsection{Antibiotic Susceptibility Pattern Against test Organisms}

Strains of Aeromonas spp. $(\mathrm{n}=59)$ characterized biochemically (39 A. hydrophila, 14 A. sobria isolates and 6 A. caviae) were tested for susceptibility to a panel of 28 antibiotics. The results are presented in Table 4 (in percen-tage). Our results show the existence of differences in some of the antibiotics tested according to the species and all Aeromonas isolates were resistance to amoxicillin, carbenicillin and ampicillin. Of the aminoglycosides antibiotics the most effective was amikacin (81.4\%). Moreover, Aeromonas hydrophila showed sensitivity values to quinolones as ciprofloxacin and norfloxacin, about 39.0 and $37.3 \%$ respectively. High resistance to first and second-generation cephalosporins (cephalothin and cefoxitin, sensitivity 8.7 and $6.8 \%$ respectively) has been detected in motile aeromonad isolates. The most potent antibiotics showing $100 \%$ activity against Aeromonas species isolated in this study were ceftriaxone, ceftazidime, cefotaxime, cefepime, while cefoperazone showed $91.5 \%$. Chloramphenicol showed the highest efficacy against the bacterial strains tested (93.2\% sensitive). Tetracycline sensitivity was $22.0 \%$ for Aeromonas spp. 


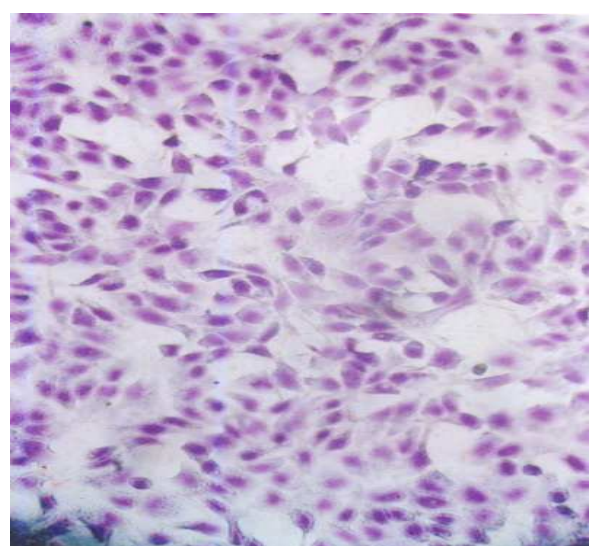

(a)

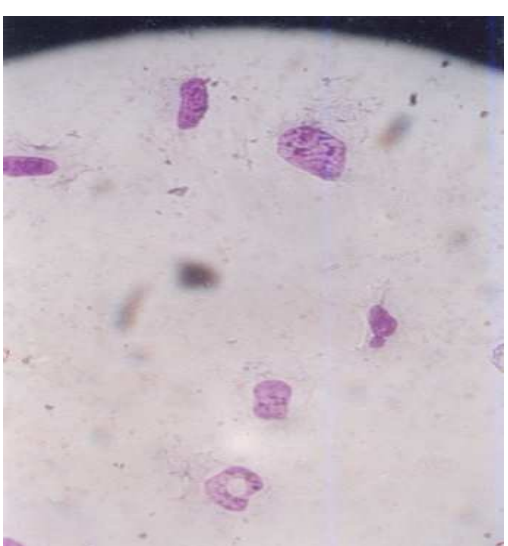

(b)

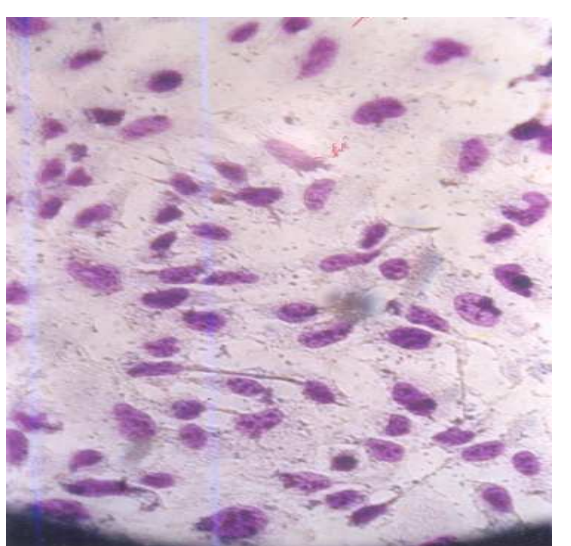

(c)

Fig. 1. Effects of culture filtrate of isolates of Aeromonas species on HEp-2 cells. (a) Confluent growth of HEp-2 cells; (b) cytotoxic effect associated with cell vacuolation (c) Adherence patterns of isolates of A. hydrophila on HEp-2 cells (Giemsa stain)

Table 4. Variations in susceptibilities (\%) among environmental and clinical isolates of Aeromonas species strains to different antibiotics /disc-diffusion method

\begin{tabular}{|c|c|c|c|c|c|c|c|c|c|c|c|c|c|c|}
\hline \multirow{3}{*}{$\begin{array}{l}\text { Antibiotics } \\
\text { used }\end{array}$} & \multicolumn{4}{|c|}{ A. hydrophelia isolates } & \multicolumn{4}{|c|}{ A. sobria isolates } & \multicolumn{6}{|c|}{ A. caviae isolates } \\
\hline & \multicolumn{2}{|c|}{ s Environmental (21) } & \multicolumn{2}{|c|}{ ) Clinical (18) } & \multicolumn{2}{|c|}{ Environmental (8) } & \multicolumn{2}{|c|}{ Clinical (6) } & \multicolumn{2}{|c|}{ Environmental (4) } & \multicolumn{2}{|c|}{ Clinical (2) } & \multicolumn{2}{|c|}{ Total 59} \\
\hline & No. & $(\%)$ & No. & $(\%)$ & No. & $(\%)$ & No. & $(\%)$ & No. & $(\%)$ & No & $(\%)$ & No. & $(\%)$ \\
\hline AMP & 0 & 0.0 & 0 & 0.0 & 0 & 0.0 & 0 & 0.0 & 0 & 0 & 0 & 0 & 0 & 0.0 \\
\hline CAR & 0 & 0.0 & 0 & 0.0 & 0 & 0.0 & 0 & 0.0 & 0 & 0 & 0 & 0 & 0 & 0.0 \\
\hline AML & 0 & 0.0 & 0 & 0.0 & 0 & 0.0 & 0 & 0.0 & 0 & 0 & 0 & 0 & 0 & 0.0 \\
\hline AMC & 6 & 28.6 & 7 & 38.9 & 3 & 37.5 & 2 & 33.3 & 1 & 25 & 1 & 50 & 20 & 33.9 \\
\hline TIC & 10 & 47.6 & 3 & 16.7 & 1 & 12.5 & 1 & 16.7 & 2 & 50 & 1 & 50 & 18 & 30.5 \\
\hline TIM & 9 & 42.9 & 3 & 16.7 & 2 & 25.0 & 2 & 33.3 & 2 & 50 & 1 & 50 & 19 & 32.2 \\
\hline PRL & 4 & 19.0 & 2 & 11.1 & 2 & 25.0 & 1 & 16.7 & 2 & 50 & 1 & 50 & 12 & 20.3 \\
\hline TZP & 9 & 42.9 & 3 & 16.7 & 2 & 25.0 & 2 & 33.3 & 2 & 50 & 1 & 50 & 19 & 32.2 \\
\hline $\mathrm{KF}$ & 2 & 9.5 & 1 & 5.6 & 0 & 0.0 & 1 & 16.7 & 1 & 25 & 0 & 0 & 5 & 8.7 \\
\hline FOX & 1 & 4.7 & 2 & 11.1 & 0 & 0.0 & 1 & 16.7 & 0 & 0 & 0 & 0 & 4 & 6.8 \\
\hline CRO & 21 & 100.0 & 18 & 100.0 & 8 & 100.0 & 6 & 100.0 & 4 & 100 & 2 & 100 & 59 & 100.0 \\
\hline CAZ & 21 & 100.0 & 18 & 100.0 & 8 & 100.0 & 6 & 100.0 & 4 & 100 & 2 & 100 & 59 & 100.0 \\
\hline CFP & 18 & 85.7 & 16 & 88.9 & 8 & 100.0 & 6 & 100.0 & 4 & 100 & 2 & 100 & 54 & 91.5 \\
\hline CTX & 21 & 100.0 & 18 & 100.0 & 8 & 100.0 & 6 & 100.0 & 4 & 100 & 2 & 100 & 59 & 100.0 \\
\hline FEP & 21 & 100.0 & 18 & 100.0 & 8 & 100.0 & 6 & 100.0 & 4 & 100 & 2 & 100 & 59 & 100.0 \\
\hline ATM & 21 & 100.0 & 18 & 100.0 & 8 & 100.0 & 6 & 100.0 & 4 & 100 & 2 & 100 & 59 & 100.0 \\
\hline IMP & 21 & 100.0 & 18 & 100.0 & 8 & 100.0 & 6 & 100.0 & 4 & 100 & 2 & 100 & 59 & 100.0 \\
\hline CIP & 16 & 76.2 & 3 & 16.7 & 1 & 12.5 & 1 & 16.7 & 2 & 50 & 0 & 0 & 23 & 39.0 \\
\hline NOR & 14 & 66.7 & 2 & 11.1 & 4 & 50.0 & 0 & 0.0 & 1 & 25 & 1 & 50 & 22 & 37.3 \\
\hline ТOB & 9 & 42.9 & 11 & 61.1 & 5 & 62.5 & 3 & 50.0 & 3 & 75 & 1 & 50 & 32 & 54.2 \\
\hline $\mathrm{AK}$ & 17 & 81.0 & 14 & 77.8 & 6 & 75.0 & 6 & 100.0 & 3 & 75 & 2 & 100 & 48 & 81.4 \\
\hline K & 11 & 52.4 & 12 & 60.0 & 4 & 50.0 & 4 & 66.7 & 2 & 50 & 1 & 50 & 24 & 40.7 \\
\hline $\mathrm{CN}$ & 13 & 61.9 & 12 & 60.0 & 5 & 62.5 & 4 & 66.7 & 2 & 50 & 1 & 50 & 36 & 61.0 \\
\hline NET & 12 & 57.1 & 17 & 85.0 & 6 & 75.0 & 5 & 83.3 & 3 & 75 & 1 & 50 & 44 & 74.6 \\
\hline $\mathrm{TE}$ & 5 & 23.8 & 6 & 33.3 & 0 & 0.0 & 1 & 16.7 & 2 & 50 & 1 & 50 & 13 & 22.0 \\
\hline $\mathrm{C}$ & 18 & 85.7 & 17 & 94.4 & 8 & 100.0 & 6 & 100.0 & 4 & 100 & 2 & 100 & 55 & 93.2 \\
\hline E & 2 & 9.5 & 1 & 5.6 & 0 & 0.0 & 1 & 16.7 & 0 & 0 & 0 & 0 & 4 & 6.8 \\
\hline SXT & 10 & 47.6 & 9 & 50.0 & 6 & 75.0 & 3 & 50.0 & 3 & 75 & 1 & 50 & 32 & 54.2 \\
\hline
\end{tabular}




\subsection{Effect of Essential Oils on Isolated Aeromonas Species Growth in Vitro}

The anti-bacterial activity of three selected essential oils against isolated Aeromonas species is summarized in Table 5. The results revealed that the selected essential oils showed antibacterial activity with varying magnitudes.

Clove, Olive and Peppermint oil showed a zone of inhibition, ranging from $10.00 \pm 0.8$ to $14.82 \pm 0.41 \mathrm{~mm}$ in diameter. They exhibited a wide spectrum of antimicrobial activity against all strains used in this study.

Minimum Inhibitory Concentration (MIC) for selected oils ranged from 12.8 to $25.6 \mathrm{mg} \mathrm{mL}^{-1}$ (Table 6). This study revealed that Clove oil showed maximum activity with MIC values $12.8 \mathrm{mg} \mathrm{mL}^{-1}$ followed by Olive and Peppermint oil with MIC values $25.6 \mathrm{mg} \mathrm{mL}^{-1}$ each against all the tested strains.

\subsection{Effect of Essential Oils Against Aeromonas Hydrophilia in Vivo}

Reactivity of cell envelop antigen with serum of tested animals was expressed in O.D. values (at 492 $\mathrm{nm}$ ) and is shown in Table 7. It indicated that the sero-reactivity of infected-essential oil treated mice (groups 1,2 and 3) was higher than that recorded in infected-non treated group (4). These increases in antibody titer increase gradually till reach peak at 3 weeks post infection.

The effect resulting from orally administrated selected essential oils on mice experimentally infected with A.hydrophilia is shown in Table 8. In control positive group (group 4) not administrated with any essential oil and infected with A.hydrophilia, the cummmulative mortality of infected mice was $70 \%$. No mortality was apparent in mice orally administrated with $1 \%(\mathrm{w} / \mathrm{v})$ clove oil $0.5 \mathrm{~mL}$ (group1) or $5 \%(\mathrm{w} / \mathrm{v})$ olive oil $0.5 \mathrm{~mL}$ (group2) for 15 days whereas $10 \%$ mortality in mice orally administrated with $5 \%(\mathrm{w} / \mathrm{v})$ Peppermint oil $0.5 \mathrm{~mL}$ (group3).

Reisolation of A.hydrophilia from different organs of dead and sacrificed mice all over experimental period gave variable results. In infected-non treated group (group 4) A.hydrophilia isolated in a percent of $100 \%$, 40, 70 and $80 \%$ from intestine, lungs, liver and spleen, respectively. While, in mice-treated with Clove (group1) or olive oil (group2) and infected, A.hydrophilia couldn't be isolated from any internal organ (Table 6). In group 3 treated with Peppermint oil and infected, A.hydrophilia isolated from intestine only in a percent of $10 \%$.

Postmortem gross examination. The noninfected mice were used as controls. The noninfected control mice had normal organ architecture with no visible lesions in the intestine, lungs, liver and spleen.

In infected non essential oil treated group (group 4), among those mice which died, the most common gross pathological findings at necropsy were severe congestion in all internal organs with necrosis.

In essential oil treated mice (group 1, 2 and 3), significantly lowered the macroscopic damage scores in comparison to untreated animals (group 4).

Histological examination. The noninfected mice The noninfected control mice had normal organ architecture with no microscopic lesions in the intestine, lungs, liver and spleen (Fig. 2a-d).

In the infected non essential oil treated group (group 4 ), abnormal histology was present in internal organs of mice infected with the isolated A. hydrophilia. Necrosis of ileal villi accompanied by focally extensive infiltration of lamina propria by large numbers of polymorphonuclear neutrophils extending along the base of intestinal crypts and infiltration of villous lamina propria by large numbers of polymorphonuclear neutrophils with segmental sloughing of intestinal epithelial cells. Representative example of these lesions is shown in Fig. 3a.

Table 5. Inhibitory activity of tested essential oils against isolated Aeromonas species (Mean \pm SD) (mm*)

\begin{tabular}{|c|c|c|c|}
\hline \multirow[b]{2}{*}{ Oil name } & \multicolumn{3}{|c|}{ Isolateslzone of inhibition } \\
\hline & A. hydrophelia & A. sobria & A. caviae \\
\hline Clove oil & $14.82 \pm 0.41$ & $13.00 \pm 0.81$ & $14.66 \pm 0.46$ \\
\hline Olive oil & $12.11 \pm 0.32$ & $11.66 \pm 0.46$ & $12.00 \pm 0.81$ \\
\hline Peppermint oil & $11.59 \pm 0.45$ & $10.00 \pm 0.81$ & $11.33 \pm 0.46$ \\
\hline
\end{tabular}

Table 6. Minimum Inhibitory Concentration (MIC) of selected essential oils (mg/mL)

\begin{tabular}{llll}
\hline & Isolates $\backslash$ MIC & \\
Oil name & A. hydrophelia & A. sobria & A. caviae \\
\hline Clove oil & 12.8 & 12.8 & 12.8 \\
Olive oil & 25.6 & 25.6 & 25.6 \\
Peppermint oil & 25.6 & 25.6 & 25.6 \\
\hline
\end{tabular}


Ahmed M.A. Mansour et al. / American Journal of Infectious Diseases 10 (1): 21-35, 2014

Table 7. Overall mean of ELISA optical density among experimental animal groups (Mean \pm SD)

\begin{tabular}{|c|c|c|c|c|}
\hline \multirow[b]{2}{*}{ Animals groups } & \multicolumn{4}{|c|}{ Weeks post infection } \\
\hline & 1 & 2 & 3 & 4 \\
\hline I & $0.480 \pm 0.006$ & $0.696 \pm 0.019$ & $0.821 \pm 0.009$ & $0.806 \pm 0.010$ \\
\hline 2 & $0.495 \pm 0.009$ & $0.743 \pm 0.009$ & $0.811 \pm 0.018$ & $0.793 \pm 0.021$ \\
\hline 3 & $0.413 \pm 0.31$ & $0.762 \pm 0.031$ & $0.791 \pm 0.021$ & $0.757 \pm 0.015$ \\
\hline 4 & $0.309 \pm 0.111$ & $0.397 \pm 0.087$ & $0.409 \pm 0.018$ & $0.411 \pm 0.017$ \\
\hline 5 & $0.121 \pm 0.003$ & $0.099 \pm 0.007$ & $0.103 \pm 0.009$ & $0.112 \pm 0.009$ \\
\hline
\end{tabular}

Cut off value $\geq 2$ was taken as positive

Table 8. Re-isolation of A.hydrophilia from different organs of dead as well as sacrificed mice during and at the end of the experiment

\begin{tabular}{lllllll}
\hline Animals groups & Intestine & Lungs & Liver & Spleen & Dead/total & Mortality rates $(\%)$ \\
\hline 1 & & $0(0 \%)$ & $0(0 \%)$ & $0(0 \%)$ & $0(0 \%)$ & $0 / 100$ \\
2 & $0(0 \%)$ & $0(0 \%)$ & $0(0 \%)$ & $0(0 \%)$ & $0 / 10$ & 0 \\
3 & $1(0 \%)$ & $0(0 \%)$ & $0(0 \%)$ & $0(0 \%)$ & $1 / 10$ & 10 \\
4 & $10(100 \%)$ & $4(40 \%)$ & $7(70 \%)$ & $8(80 \%)$ & $7 / 10$ & 70 \\
5 & $10(0 \%)$ & $0(0 \%)$ & $0(0 \%)$ & $0(0 \%)$ & $0 / 10$ & 0 \\
\hline
\end{tabular}

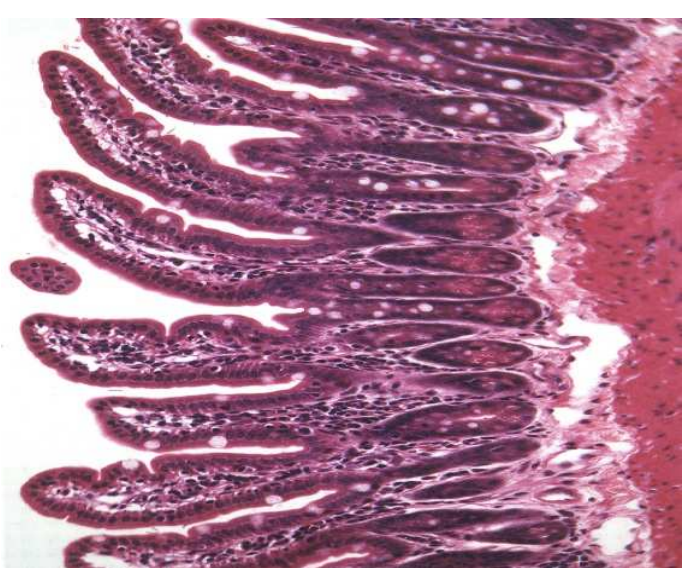

(a)

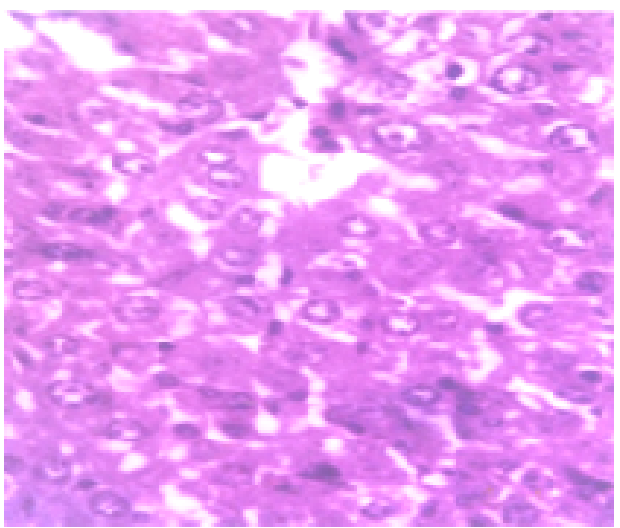

(c)

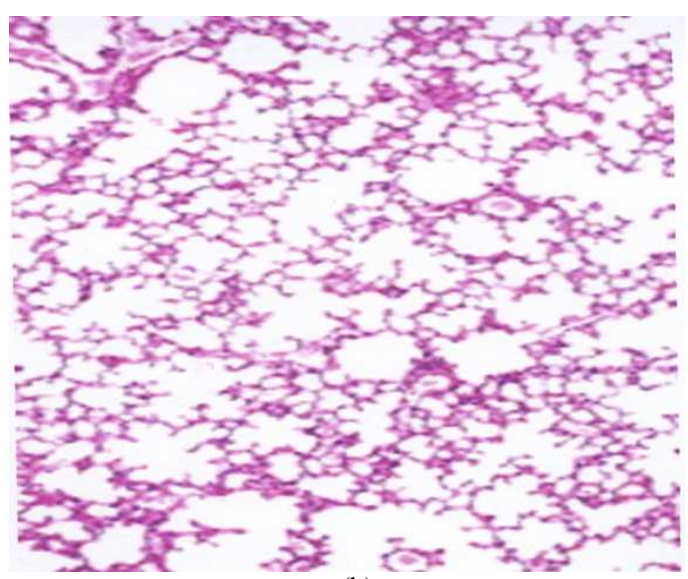

(b)

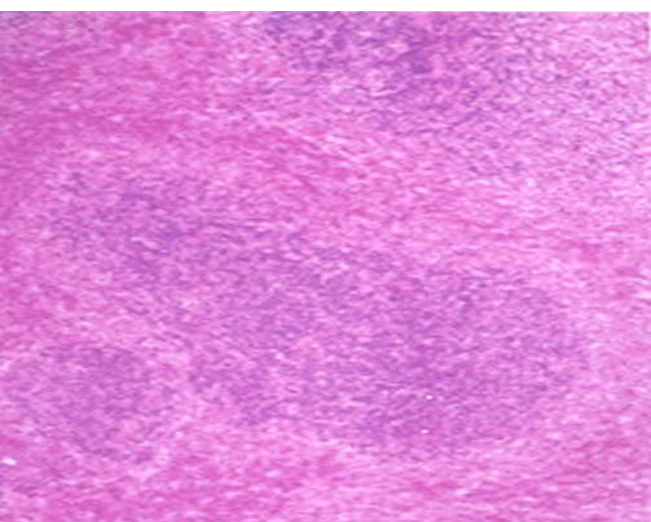

(d)

Fig. 2. Histopathological analysis in the non infected mice which were used as controls. Tissues are as indicated (Fig. 2a-d), intestine; lungs; liver and spleen respectively with H\&E staining had normal organ architecture with no microscopic lesions (Magnifications, $\times 100)$ 


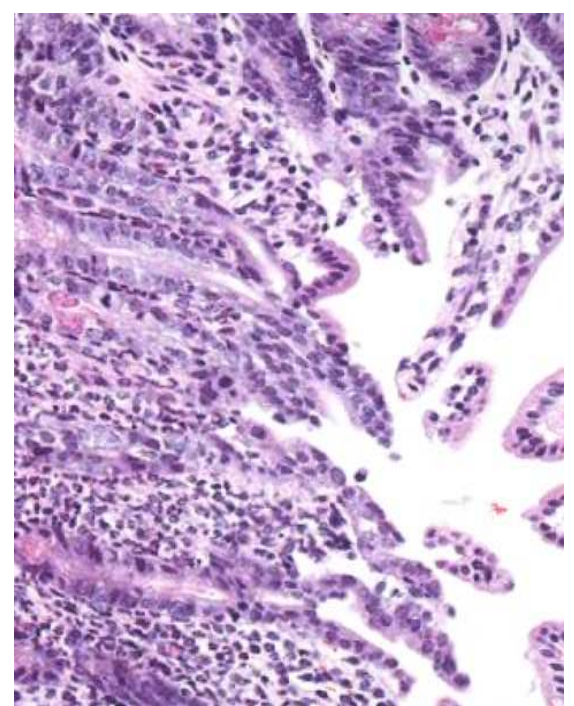

(a)

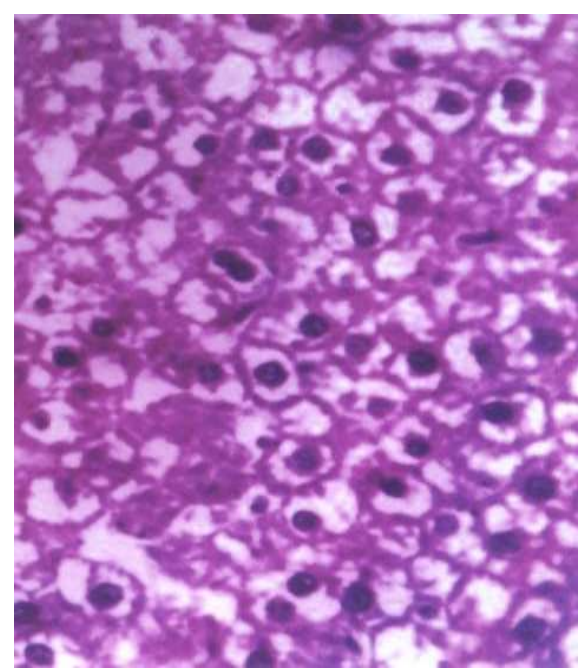

(c)

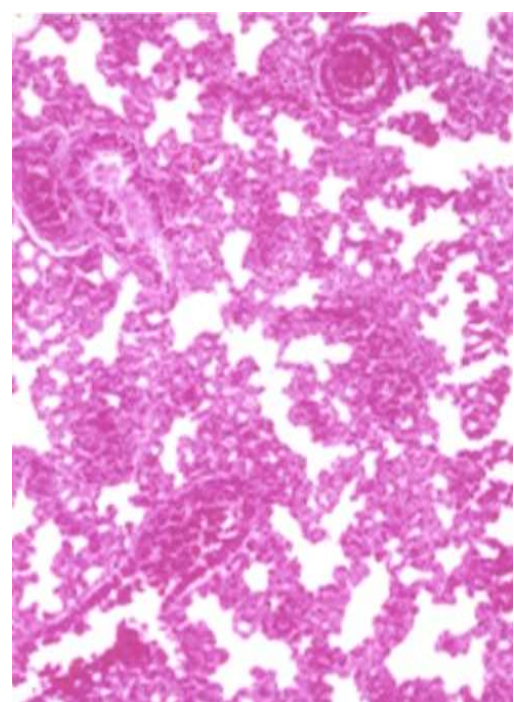

(b)

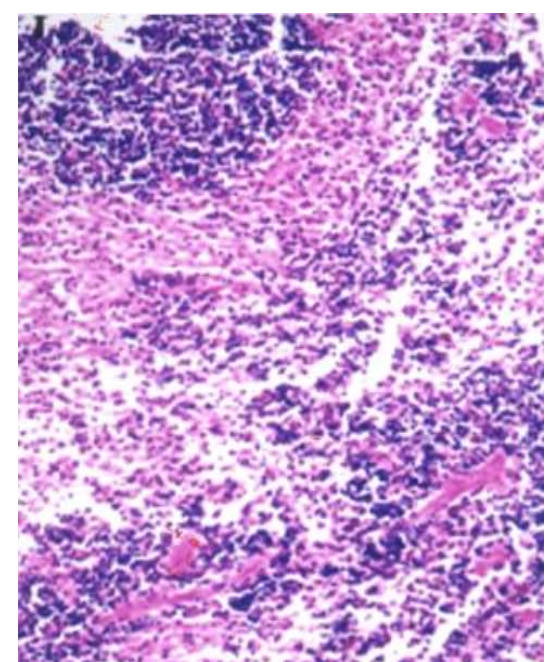

(d)

Fig. 3. Histopathological analysis with $\mathrm{H}$ and $\mathrm{E}$ staining in the infected nontreated mice (a) intestine showed necrosis of ileal villi accompanied by focally extensive infiltration of lamina propria by large numbers of polymorphonuclear neutrophils (b) Lung showed marked vascular congestion and alveolar hemorrhage (c) Liver showed coagulative necrosis of the hepatic parenchyma and vascular degeneration (d) Spleen showed marked necrosis in splenic follicle and apoptotic cells in the red pulp (Magnifications, $\times 100$ )

The lung section (Fig. 3b) had marked vascular congestion, alveolar hemorrhage and widening of the interstitium. The liver section (Fig. 3c) showed prominent coagulative necrosis of the hepatic parenchyma and vascular degeneration. Several inflammatory cells were seen in the sinusoids. In the spleen section of nontreated mice (Fig. 3d), the splenic follicle exhibited necrosis and apoptotic cells in the red pulp in proximity to the lymphoid follicle. Lymphocytic depletion was seen in the white pulp.

In the essential oil treated groups (group1,2 and 3), intestinal segments from mice challenged with A.hydrophilia showed highly preserved histological architecture of the lamina propria and submucosa 
throughout the small intestine (Fig. 4a). There were minimal damages to the epithelial layer and the heights of the villi were preserved with mild infiltration of inflammatory cells inside the villi. The lung (Fig. 4b) section showed resolution of stages of pneumonia had focal thickening of alveolar septa, lymphohistiocytic infiltrates and neutrophils with scanty edematous in some alveoli. There was no evidence of alveolar hemorrhage or vascular congestion. In the liver (Fig. 4c) section, occasional lobular and perivascular lymphohistiocytic infiltrates.
Focal areas of necrosis; congested and dilated sinusoids were also observed.

The increased macrophages in the red pulp and marked lymphoid activation in the splenic follicles, with germinal center formation, were present in the spleen section (Fig. 4d). Tissues from A. hydrophila infected and essential oils treated mice were relatively normal. Overall; architectural analysis revealed to us that mice infected with $A$. hydrophila without treatment with essential oils exhibited more severe pathologies.

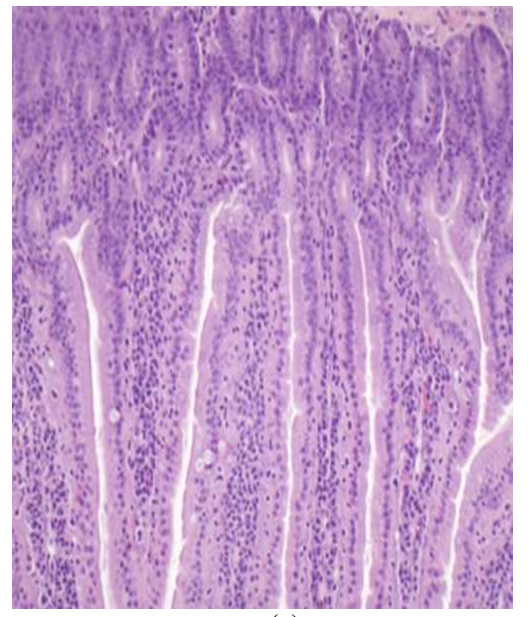

(a)

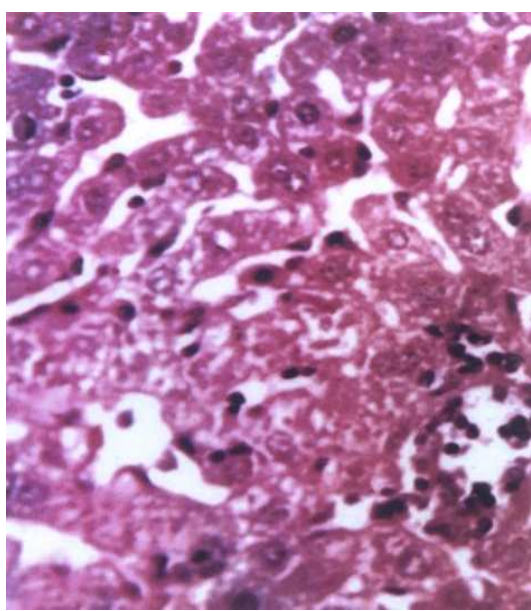

(c)

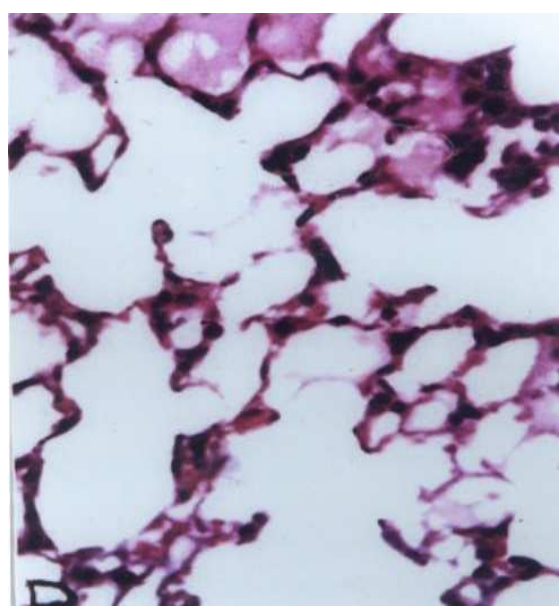

(b)

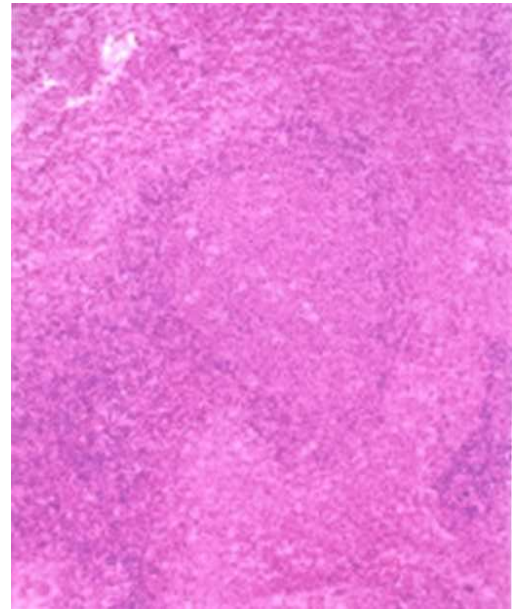

(d)

Fig. 4. Histopathological analysis with H\&E staining in the essential oil treated mice (a) intestine showed minimal damages to the epithelial layer and the heights of the villi were preserved (b) Lung showed resolution of stages of pneumonia, lymphohistiocytic infiltrates and neutrophils with scanty edematous in some alveoli (c) Liver showed occasional lobular and perivascular lymphohistiocytic infiltrates (d) Spleen showed marked lymphoid activation in the splenic follicles, with germinal center formation, were present (Magnifications, $\times 100$ ) 


\section{DISCUSSION}

Aeromonas spp. are widely distributed in the environment, particularly in fresh and brackish water, sewage, marine water and drinking water. There are also various reports of the presence of these bacteria in food (Sechi et al., 2002). Most research on Aeromonas has focused on their potential to cause gastro-enteritis both in adults and infants, they are also recognized as causes of infections in immune-compromised hosts which may progress to septicemia (Kuhn et al., 1997). A high ability of Aeromonas species to live under a wide variety of environmental conditions in natural waters has been observed by Paniagua et al. (1990). The microorganism has been isolated over wide ranges of salinity, conductivity, temperature, $\mathrm{pH}$ and turbidity. In this study, Aeromonas strains were identified at the phenotypic level by integrating a conventional biochemical scheme with new biochemical key tests able to avoid a misidentification of each species with the nearest neighbours. The finding of 59 strains with phenotypes sharing characters belonging to different species, A. hydrophila and A. caviae and A. sobria isolates. The high incidence of Aeromonas species in farm animals may therefore, only reflect constant exposure to water containing the organism (Sechi et al., 2002). This would appear to be substantiated by the significant overall correlation found between its presence in animal faeces and the available drinking water. The cow, sheep, goats and camels groups studied were by nature 'free' roaming animals with ready access to untreated water with a high likelihood of contamination with Aeromonas species The highest incidence of isolation was from well water samples $38.2 \%$ (21 out of 55.samples) and chlorinated tap water samples $23.1 \%$ (12 out of 52 samples) which agreed with Araujo et al. (1991). The data reported in this study indicates that the distributions of virulence factors, that regulate the pathogenicity of Aeromonads, are different in clinical and enviromental samples. The haemolysin and protease production was found more frequently in the clinical samples whereas gelatinase, which may be important in colonization through the disruption of the intestinal barrier, was found exclusively in the clinical samples (Sechi et al., 2002). For many bacterial species the ability to adhere to eukaryotic cells is the first step in the colonization and development of disease. The cytopathic effect induced on the HEp- 2 cells infected by Aeromonas spp. was more evident when the cells were infected with strains which produced toxins, such as haemolysin and protease. The study also found a greater prevalence of haemolysin, protease and gelatinase production, as well as higher adhesion capacity, among strains isolated from clinical samples. These findings are in agreement with those reported by Sechi et al. (2002). Overall, in this study, adhesive and cytotoxic properties were more present in clinical than in environmental strains. Similar results were reported by Carrello et al. (1988) who found that clinical strains of $A$. hydrophila were more adhesive on Hep-2 cells than environmental strains, while the opposite was found by Sechi et al. (2002) for isolates of A. veronii biovar sobria. In the present study, about (88.9\%) of A. Hydrophila clinical isolates were positive for Congo red binding test (Table 6). Paniagua et al. (1990) reported that all motile Aeromonas take up Congo red dye. In our study, the majority of the clinical isolates of A. hydrophila (94.4\%) showed serum resistance properties. Additionally, the bactericidal activity of antibodies and 'complement-like' bactericidal activity is operative in the intestinal mucosa, contributing to the colonization properties of a variety of bacterial pathogens. Hence, the serum resistance properties of A. hydrophila could also play an essential role in intestinal colonization. It has been suggested that the ability of some $A$. hydrophila strains to resist complement mediated killing could result in bacteraemia and other invasive diseases associated with Aeromonas infection (Merino et al., 1996).

Binding of crystal violet to virulent strains allows the rapid and simple differentiation of virulent and avirulent strains of Aeromonas species (Mahmoud and Tanios, 2008). Paniagua et al. (1990) found that all the CV+ strains examined harboured a plasmid and demonstrated other virulence-associated attributes that have been reported to be plasmid determined. In the present study, $66.7 \%$ A. hydrophila clinical isolates were positive for crystal violet binding activity (Table 6). The obtained results agree with Paniagua et al. (1990).

Many bacteria produce surface antigens which enable adherence to epithelial cells in vivo and may promote agglutination of different species of erythrocytes (RBCs) in vitro. Such adherence factors are in many cases encoded by plasmids (Burke et al., 1986). Haemagglutination of different animal erythrocyte systems have been used to type strains of mesophilic aeromonads. There is evidence that haemagglutination patterns vary under different test conditions Burke et al. (1986). In the present study non agglutinating isolates were more likely to be $A$. caviae than $A$. hydrophila or $A$. sobria and this confirms previous findings Burke et al. (1986). 
In conclusion, these findings indicate that aeromonads have the potential to cause human illness and confirm the role of water as vehicles for Aeromonas diseases. This study also demonstrated that the multifactorial nature of the diseases and the influence of environmental conditions in the expression of the putative virulence properties

Factors of virulence represented by extracellular proteases, hemolysins and cytotoxins were produced by nearly all virulent and avirulent strains of $A$. hydrophila to the same extent. This fact and the absence of correlation between the corresponding activities and the degree of virulence may indicate that qualitative factors rather than quantitative ones are involved in the pathologic process.

Antibiotics are generally administered to animals and human prophylactically and therapeutically against microbial diseases and subtherapeutically as growth promoters .Potential consequences of antibiotic use in culture and animal feeds are development of drug resistant bacteria, transfer of resistant characteristics to bacteria and reduced efficacy of antibiotic treatment for human and animal diseases.

An increasing incidence of multidrug resistance among Aeromonas spp. isolates, which are emerging opportunistic human pathogens, has been observed worldwide. This can be attributed to the horizontal transfer of mobile genetic elements like plasmids and class 1 integrons (Jacobs and Hafizah, 2006). Aeromonas spp. are known to be intrinsically susceptible to all antibiotics active against nonfastidious Gram-negative bacilli, except for many $\beta$ lactams, due to the production of multiple inducible, chromosomally encoded $\beta$-lactamases (Jones and Wilcox, 1995). In this study all strains were resistant to amoxicillin, carbenicillin and ampicillin.

Of the aminoglycosides antibiotics the most effective was amikacin $(81.4 \%)$ which is similar to the findings of Jones and Wilcox (1995) who reported that Aeromonas spp. usually retain their aminoglycoside susceptibility.

The most potent antibiotics showing $100 \%$ activity against Aeromonas species isolated in this study were ceftriaxone, ceftazidime, cefotaxime, cefepime, while cefoperazone showed $91.5 \%$. Commonly, these antibiotics used as first therapeutic options for Aeromonas infections in humans (Alcaide et al., 2010).

Chloramphenicol showed the highest efficacy against the bacterial strains tested (93.2\% sensitive). Similarly, all of the investigated strains were susceptible to chloramphenicol, Jones and Wilcox (1995) reported that Chromamphenicol resistance is an extremely rare trait in
Aeromonas spp. Tetracycline sensitivity was $22.0 \%$ for Aeromonas spp. Ko et al. (1996) found as many as $49 \%$ tetracycline-resistant Aeromonas spp., The increasing resistance to antibiotic represents the main factor justifying the need to find and/or develop new antimicrobial agents. Plant essential oils and extracts have been used for many thousands of years, in food preservation, pharmaceuticals, alternative medicine and natural therapies (Maddox et al., 2010). It is necessary to investigate those plants scientifically which have been used in traditional medicine to improve the quality of healthcare.

A method frequently used to screen plant extracts for antimicrobial activity is the agar well diffusion technique. The zones of inhibition formed by the essential oils (varied from $10.00 \pm 0.81$ to $14.82 \pm 0.41$ ) are reported In Table 5. Almost all selected essential oils were found to be effective against the tested Aeromoas species (Wan et al., 1998). The results of this study revealed that, the essential oils Clove; Olive and Peppermint oil had inhibitory effect on isolated Aeromoas species. Clove had MIC $12.8 \mathrm{mg} \mathrm{mL}^{-1}$, whereas Olive and Peppermint oil had MIC $25.6 \mathrm{mg}$ $\mathrm{mL}^{-1}$ each (Table 6). Many authors ruled out the use of antibiotics and favored the use of essential oils as Clove; Olive and Peppermint oil that exhibited the antimicrobial activity against wide range of gram positive and gram negative bacteria in very low concentrations without mutageicity (Wan et al., 1998; Maddox et al., 2010). Essential oils have been tested for in vitro and in vivo antimicrobial activity and some have demonstrated to be possessing potential antimicrobial potential. Their mechanism of action appears to be predominantly on the cell membrane by disrupting its structure thereby causing cell leakage and cell death, secondary actions may be by blocking cell membrane synthesis and inhibition of cellular respiration. They readily penetrate into cell membrane and exert their biological effect because of high volatility and lipophilicity of essential oils (Inouye, 2003). A growing interest in using herbs and other material therapies in animal production has been made just a complementary medicine. These results showed that daily administration of essential oil enhance antibody levels in all treated groups (1 and 2 and 3). Similar results were reported by Subeena and Navaraj (2012) who Showed that these essential oils had some immmuostimlatory effects on these immunological factors such as antibody titters, total white blood cells and serum bactericidal activity in some test groups. Treatment with essential oil Clove or Olive for 15 days 
led to significant clearance of A. hydrophilia from the all of animals exhibiting negative $A$. hydrophilia culture compared with Group 4 (the infected untreated); however, A. hydrophilia was detected in intestine of one remaining infected mice treated with Peppermint oil (Group 3) by microbiological results. The treated animals had minimal histopathological changes and lower bacterial loads in the organs examined. These results suggested that the essential oils have potential value as an additional or supporting treatment in gastrointestinal inflammations. This correlated well with some biological effects of essential oil such as its antiseptic properties against a range of microbial agents and, recently, its anti-inflammatory potential, both in vitro and in vivo Takarada et al. (2004). These results encourage the use of essential oils as substitute for antibiotics and can be added to the animal feeds in very low concentrations without any harmful effect.

\section{CONCLUSION}

Aeromonas species was isolated more frequently from goats (21.7\%) than from other animal groups sampled and isolated more frequently from well water (38.2\%) than chlorinated supplies $(23.0 \%)$. The most potent antibiotics against Aeromonas species isolated in this study were ceftriaxone, ceftazidime, cefotaxime, cefepime. Clove, Olive and Peppermint oil exhibited a wide spectrum of antimicrobial activity.

\section{REFERENCES}

Alcaide, E., M.D. Blasco and C. Esteve, 2010. Mechanisms of quinolone resistance in Aeromonas species isolated from humans, water and eels. Res. Microbiol., 161: 40-45. DOI: 10.1016/j.resmic.2009.10.006

Ali, A. and J. Hossein, 2010. A review on Occurrence and characterization of the Aeromonas species from Marine Fishes. World J. Fish Marine Sci., 2: 519-523.

Annapurna, E. and S.C. Sanyal, 1977. Enterotoxicity of Aeromonas hydrophila. J. Med. Microbiol., 10: $317-$ 323. PMID: 894697

Araujo, R.M., R.M. Arribas and P. Pares 1991. Distribution of Aeromonas species in waters with different levels of pollution. J. Applied Bacteriol., 71: 182-186. PMID: 1917727

Atkinson, H.M. and T.J. Trust, 1980. Hemagglutination properties and adherence ability of Aeromonas hydrophila. Infect. Immun., 27: 938-946. PMID: 6103874
Bag, P.K., P. Bhowmik, T.K. Hajra, T. Ramamurthy and P. Sarkar et al., 2008. Putative virulence traits and pathogenicity of Vibrio cholerae non-O1, non-O139 isolated from surface waters in Kolkata, India. Applied Environ. Microbiol., 74: 5635-5644. DOI: 10.1128/AEM.00029-08

Bhowmik, P., P.K. Bag, T.K. Hajra, D.P.R. Sarkar and T. Ramamurthy, 2009. Pathogenic potential of Aeromonas hydrophila isolated from surface waters in Kolkata, India. J. Med. Microbiol., 58: 15491558. PMID: 19713362

Burke, V., M. Cooper and J. Robinson, 1986. Haemagglutination patterns of aeromnonas spp. Related to species and source of strains. Aust. J. Exp. Biol. Med. Sci., 64: 563-570. PMID: 3593124

Carrello, A., K.A. Silburn, J.R. Budden and B.J. Chang, 1988. Adhesion of clinical and environmental Aeromonas isolates to Hep-2 cells. J. Med. Microbiol., 26: 19-27. PMID: 2897470

Chang, C. and J.F. Miller, 2006. Campylobacter jejuni colonization of mice with limited enteric flora. Infect. Immun., 74: 5261-5271. PMID: 16926420

CLSI, 2010. Performance Standards for antimicrobial susceptibility testing: Seventeenth information supplement. Clinical and Laboratory and Standards Institute.

Daskalov, H., 2006. The importance of Aeromonas hydrophila in food safety. Food Control., 17: 474483. DOI: 10.1016/j.foodcont.2005.02.009

Delaquis, P.J., K. Stanich, B. Girard and G. Mazza, 2002. Antimicrobial activity of individual and mixed fractions of dill, cilantro, coriander and eucalyptus essential oils. Int. J. Food Microbiol., 74: 10-109. DOI: 10.1016/S0168-1605(01)00734-6

FAO\OIEIWHO, 2006. Antimicrobial use in aquaculture and antimicrobial resistance. Report of a joint FAO\OIE\WHO, Expert Consultation on Antimicrobial Use in Aquaculture and Antimicrobial Resistance, Department of Food Safety, Zoonoses and food born Diseases World Health Organization.

Farzaneh, E., G.R. Moshtaghi-Kashanian and H. Mohammad, 2011. Consumption of corn or olive oil have protective effects due to production of proinflammatory cytokines; immunological responses to dietary oil. Pak. J. Nut., 10: 773-780. DOI: 10.3923/pjn.2011.773.780

Freeman, D.J., F.R. Falkiner and C.T. Keane, 1989. New method for detecting slime production by coagulase negative staphylococci. J. Clin. Pathol., 42: 872-874. DOI: $10.1136 /$ jcp.42.8.872 
Grim, C.J., E.V. Kozlova, J. Sha, E.C. Fitts and C.J. van Lier et al., 2013. Characterization of Aeromonas hydrophila wound pathotypes by comparative genomic and functional analyses of virulence genes. MBIO, 4: 1-13. PMID: 23611906

Hassan, M., B. Bazargani-Gilani, T. Amir and E. Hadi, 2012. A cytotoxicity and comparative antibacterial study on the effect of Zataria multiflora Boiss, Trachyspermum copticum essential oils and Enrofloxacin on Aeromonas hydrophila. Avicenna J. Phytomedicine., 2: 188-195.

Inouye, S., 2003 Laboratory evaluation of gaseous essential oils (Part1). Int. J. Armotherapy, 13: 95107. DOI: 10.1016/S0962-4562(03)00081-X

Jacobs, L. and Y.C. Hafizah, 2006. Characterization of integrons and tetracycline resistance determinants in Aeromonas spp. isolated from South African aquaculture systems. Int. J. Food Microbiol. PMID: 17173998

Jones, B.L. and M.H. Wilcox, 1995. Aeromonas infections and their treatment. J. Antimicrob. Chemother., 35: 453-461. PMID: 7628980

Ko, W.C., K.W. Yu, C.Y. Liu, C.T. Huang and H.S. Leu et al., 1996. Increasing antibiotic resistance in clinical isolates of Aeromonas strains in Taiwan. Antimicrob. Agents Chemother., 40: 1260-1262. PMID: 8723478

Kuhn, I., M.J. Albert, M. Ansaruzzaman, N.A. Bhuiyan and S.A. Alabi et al., 1997. Characterization of Aeromonas spp. isolated from humans with diarrhea, from healthy controls and from surface water in Bangladesh. J. Clin. Microbiol., 35: 369-373. PMID: 9003598

Lugtenberg, B., J. MeUers, R. Peters, P. van der Hoek and L. Van Alphen, 1975. Electrophoretic resolution of the major outer membrane protein of Escherichia coli K-12 into four bands. FEBS Lett., 58: 254-258. PMID: 773686

Maddox, C.E., L.M. Laur and L. Tian, 2010. Antibacterial activity of phenolic compounds against the phytopathogen Xylella fastidiosa. Curr. Microbiol., 60: 53-58. PMID: 19813054

Mahmoud, A.M. and A.I. Tanios, 2008. Pathogenicity of Aeromonas hydrophila in chickens. Egypt. J. Comp. Path. Clin. Path., 21: 88-110.

Merino, S., X. Rubires, A. Aguilar, S. Alberti and S. Hernandez-Alles et al., 1996. Mesophilic Aeromonas sp. serogroup O:11 resistance to complement-mediated killing. Infect. Immun., 64: 5302-5309. PMID: 8945581
Okmen, G., A. Ugur, N. Sarac and T. Arslan, 2012. In vivo and in vitro antibacterial activities of some essential oils of Lamiacae species on Aeromonas salmonicida isolates from cultured Rainbow Trout, Oncorhynchus mykiss. J. Anim. Vet. Adv., 11: 2762-2768.

Paniagua, C., O. Rivero, J. Anguita and G. Naharro, 1990. Pathogenicity factors and virulence for rainbow trout (Salmo gairdneri) of motile Aeromonas spp. Isolated from a River. J. Clin. Microbiol., 28: 350-355. PMID: 2312678

Prudent, D., F. Perineau, J.M. Bessiere, G.M. Michel and J.C. Baccou, 1995. Analysis of the essential oil of wild oregano from Martinique (Coleus aromaticus Benth.)-Evaluation of its bacterioatatic and fungistatic properties. J. Essen Oil Res., 7: 165-173. DOI: $10.1080 / 10412905.1995 .9698492$

Santos, J.A., C.J. Gonzales, A. Otero and M.L. GarciaLopez, 1999. Haemolytic activity and siderophore production in different Aeromonas species isolated from fish. Applied Environ. Microbiol., 65: 56125614.

Sanyal, S.C., S.J. Singh and P.C. Sen, 1975. Enteropathogenicity of Aeromonas hydrophila and Plesiomonas shigelloides. J. Med. Microbiol., 8: 195-198. DOI: 10.1099/00222615-8-1-195

Sechi, L.A., A. Deriu, M.P. Falchi, G. Fadda and S. Zanetti, 2002. Distribution of virulence genes in Aeromonas spp. isolated from Sardinian waters and from patients with diarrhoea. J. Applied Microbiol., 92: 221-227. PMID: 11849349

Subeena, B.S. and P.S. Navaraj, 2012. Synergistic effect of plant extracts supplemented diets on immunity and resistance to Aeromonas hydrophila in mystus keletius. J. Pharma. Biol. Sci., 2: 30-36.

Takarada, K., R. Kimizuka, N. Takahashi, K. Honma and K. Okuda et al., 2004. A comparison of the antibacterial efficacies of essential oils against oral pathogens. Oral Microbiol. Immunol., 19: 61-64. DOI: 10.1046/j.0902-0055.2003.00111.x

Tissen, P., 1985. Practice and Theory on Enzyme Immunoassays. In: Laboratory Techniques in Biochemistry and Molecular Biology, Burdon, R.H. and P.H. Knippenberg, (Eds.).

Turker, H., A.B. Yildirim, F.P. Karakas and H. Koyluoglu, 2009. Antibacterial activities of extreacts from some Turkish endemic plants on common fish pathogens. Turk. J. Biol., 33: 73-78. 
Ahmed M.A. Mansour et al. / American Journal of Infectious Diseases 10 (1): 21-35, 2014

Wan, J., A. Wilcock and M.J. Coventry, 1998. The effect of essential oils of basil on the growth of Aeromonas hydrophila and Pseudomonas fluorescens. J. Applied Microbiol., 84: 152-158. PMID: 9633630
Wohlgemuth, K., R.L. Pierce and C.A. Kirkbride, 1972. Bovine abortion associated with Aeromonas hydrophila. J. Am. Vet. Med. Ass., 160: 1001-1002. PMID: 5014883 